\title{
A CONSTRUÇÃO DE UM PROCESSO INTERDISCIPLINAR DE HUMANIZAÇÃO À LUZ DE FREIRE ${ }^{1}$ THE CONSTRUCTION OF AN INTERDISCIPLINARY HUMANIZATION PROCESS IN THE LIGHT OF FREIRE \\ LA CONSTRUCCIÓN DE UM PROCESO INTERDISCIPLINARIO DE HUMANIZACIÓN SEGÚN EL FREIRE
}

\author{
Dirce Stein Backes ${ }^{2}$,Wilson DaniloLunardi Filho ${ }^{3}$, Valéria Lerch Lunardit
}

\begin{abstract}
${ }^{1}$ Texto elaborado a partir da Dissertação de Mestrado em Enfermagem “A construção de um espaço dialógico-reflexivo com vistas à humanização do ambiente hospitalar” do Curso de Mestrado em Enfermagem do Programa de Pós-Graduação em Enfermagem (PPGEnf) da Fundação Universidade Federal do Rio Grande (FURG).

${ }^{2}$ Enfermeira. Mestre em Enfermagem pela FURG.

${ }^{3}$ Enfermeiro. Doutor em Enfermagem. Professor Orientador (PPGEnf/FURG).

${ }^{4}$ Enfermeira. Doutora em Enfermagem. Professora Co-orientadora (PPGEnf/FURG).
\end{abstract}

PALAVRAS-CHAVE: Enfermagem. Equipe de assistência ao paciente. Ética.

KEYWORDS: Nursing. Patient care team. Ethics.

PALABRAS CLAVE: Enfermería. Grupo de atención al paciente. Ética.
RESUMO: Num mundo complexo e competitivo, torna-se cada vez mais difícil encontrar estratégias para a resolução de problemas no contexto profissional e institucional. O grande desafio está em construir elementos de reflexão e estratégias de intervenção capazes de resgatar valores básicos coerentes com a ética profissional e o respeito à dignidade humana, como balizadores para o desenvolvimento de um processo de humanização institucional. Por meio do método de Paulo Freire, com base no diálogo e reflexão crítica sobre a realidade concreta, objetivou-se construir um processo interdisciplinar, com vistas à humanização do ambiente hospitalar, a partir de lideranças pertencentes à equipe multiprofissional da saúde, perfazendo o total de dezoito membros. Emergiram como temas geradores, dentre outros: humanizar-se para humanizar; o ser humano - um ser de relações dialógicas; a humanização passa pela comunicação e decorre do acolhimento e vínculo afetivo.

ABSTRACT: In a complex and competitive world, it becomes more and more difficult to visualize and find action and collectively-based strategies to solve problems in the professional and institutional context. The greatest challenge lies in constructing elements of reflection and intervention strategies able to rescue basic values coherent with professional ethics and respect to human dignity, indicators for the development of an institutional humanization process. Through Paulo Freire's method, based on the dialogue and critical reflection about one's concrete reality, we aimed at constructing an interdisciplinary process in order to humanize the hospital environment. Among others, the following subjects were generated: to be human in order to humanize; the human being - a being of dialogical relations; humanization implies communication and is a result of welcoming and emotional bonds.

RESUMEN: En un mundo complejo y competitivo, se torna cada vez más difícil visualizar y encontrar estratégias de acción y enfrentamiento colectivos para la solución de problemas en el contexto profesional e institucional. El gran reto está en construir elementos de reflexión y estratégias de intervención capaces de rescatar valores básicos coherentes con la ética profesional y el respeto a la dignidad humana, como para el desarrollo de un proceso de humanización institucional. Por medio del método de Paulo Freire, con base en el diálogo y la reflexión crítica sobre la realidad concreta, se propuso construir un proceso interdisciplinario, con miras a la humanización del ambiente hospitalario, con liderazgon pertenecientes al equipo multiprofesional de la salud, con un total de dieciocho profesionales. Emergieron como temas generadores, entre otros: humanizarse para humanizar, el ser humano un ser de relaciones dialógicas; la humanización pasa por la comunicación, este decurre de la acogido y del vinculo afectivo.
Endereço:

Dirce Stein Backes

Rua Marechal Deodoro, 855

96020-220 - Pelotas, RS.

E-mail: backesdirce@ig.com.br
Artigo original: Relato de Experiência

Recebido em: 15 de fevereiro de 2005

Aprovação final: 31 de março de 2005 


\section{CONSIDERAÇÕES INICIAIS}

A humanização, por ser mais do que um ato humanitário, requer a implementação de um processo interdisciplinar reflexivo acerca dos princípios e valores que regem a prática de diferentes profissionais de saúde em busca da sua dimensão ética. Falar em humanização, no ambiente hospitalar, pressupõe, além de um tratamento digno, solidário e acolhedor por parte dos trabalhadores ao seu principal alvo de trabalho - o doente/ser fragilizado - uma nova postura ética e relacional que permeie todas as atividades profissionais e processos de trabalho institucionais. Logo, humanização significa considerar a essência do ser humano, o respeito à individualidade e às diferenças profissionais, bem como a necessidade da construção de um espaço concreto nas instituições de saúde o qual legitime o aspecto humano de todas as pessoas envolvidas na assistência. ${ }^{1}$

O profissional poderá chegar a ser sujeito e agente de mudança, através da ação-reflexão sobre sua realidade concreta. Quanto mais o profissional reflete sobre a sua realidade subjetiva, mais se torna consciente e capaz de intervir na realidade objetiva e, dessa forma, transformá-la. Portanto, o ser humano passa a ser sujeito e agente de mudança por meio da reflexão a respeito do ambiente e da sua situação concreta, o que lhe permite o seu próprio desenvolvimento e crescimento. ${ }^{2,3}$

Os profissionais da saúde, ao refletirem sobre as condições e relações de trabalho e o seu modo de agir, podem inserir-se de maneira crítica e consciente, na realidade. Problematizar a temática da humanização, mais especificamente num espaço relacional, implica uma reflexão dialógica e crítica sobre os princípios e valores que norteiam a prática dos profissionais, no sentido de torná-los sujeitos e agentes de transformação. ${ }^{2-5}$ Daí o entendimento deste processo como necessariamente interdisciplinar, pois suas práticas, decorrentes de uma problemática e de uma necessidade comum, são entendidas "como promovendo mudanças estruturais, gerando reciprocidade, enriquecimento mútuo, com uma tendência à horizontalização das relações de poder entre os campos implicados". 4:113
Desenvolver um programa de humanização institucional pressupõe transpor barreiras disciplinares nas quais os profissionais se encontram freqüentemente inseridos. É preciso entender, no entanto, que não são as situações-limite* e/ou as barreiras disciplinares em si mesmas geradoras de desumanização, mas a percepção que o ser humano tem delas num dado momento, como obstáculos insuperáveis. Assim, "para alcançar a meta da humanização, que não se consegue sem o desaparecimento da opressão desumanizante, é imprescindível a superação das situações-limite em que a pessoa humana se acha coisificada". ${ }^{5: 95}$ A conscientização, nesse processo, não consiste no reconhecimento apenas subjetivo da situação; pelo contrário, prepara o profissional, no plano da ação, para enfrentar os obstáculos à humanização.

A construção de uma nova práxis no espaço interdisciplinar, norteada por princípios éticos e humanitários, desenvolve-se, basicamente, através do processo dialógico e reflexivo. O diálogo, no entanto, não significa somente ouvir o outro, mas também desafiá-lo, problematizando a situação existencial, para uma possível transformação da realidade. O diálogo não pode ser caracterizado como um ato passivo ou parcial, já que exige um entrar sensível no mundo do outro, histórico e cultural, para compreender o movimento dinâmico que se estabelece em torno do sujeito. É fundamental compreender e valorizar a dimensão histórica e, ainda, notar que toda cultura que poderia ser considerada arcaica e primitiva contém, nela própria, uma mistura de sabedoria, de verdades profundas, de conhecimentos e de erros e superstições. ${ }^{5}$

A reflexão crítica e dialógica pode, então, concretizar-se, mediante a experiência da abertura ao mundo e aos outros, à procura de respostas às múltiplas perguntas. Nessa perspectiva, “o sujeito que se abre ao mundo e aos diferentes saberes inaugura, com seu gesto, a relação dialógica que se confirma como inquietação e curiosidade, como inconclusão em permanente movimento na história". 2:136

O diálogo requer uma relação horizontal de pessoa para pessoa sobre o objeto e pressupõe, inicialmente, abertura e desvelamento da realidade pessoal a fim de, efetivamente, estabelecer uma reflexão

\footnotetext{
* Situações-limite são as situações que desafiam de tal forma a prática do ser humano, que é necessário enfrentá-las e superá-las para prosseguir. Elas não devem ser contornadas, mas analisadas, enfrentadas e estudadas em suas múltiplas contradições, sob pena de reaparecerem mais adiante com força redobrada. ${ }^{2}$ Não são situações insuperáveis, além das quais nada mais existiria. Logo, caracterizam o possível não experimentado como situação ameaçadora. Não são o contorno infranqueável onde terminam as possibilidades, mas a margem real onde começam todas as possibilidades. Não são as fronteiras entre o ser e o nada, mas a fronteira entre o ser e o ser mais. Ao se separarem do mundo, ao separar sua atividade de si mesmos, ao ter o ponto de decisão de sua atividade em si, em suas relações com o mundo e com os outros, os homens ultrapassam as 'situações-limite', que não devem ser tomadas como barreiras insuperáveis. ${ }^{5}$
} 
dialógica no nível coletivo. O diálogo requer, ainda, um conhecimento prévio da realidade pessoal e profissional: encontros efetivos com a subjetividade do outro para diminuir a distância entre o sujeito e o objeto. Em suma, o diálogo busca estabelecer um significado coletivo e horizontalizado entre os diversos saberes, para a superação das situações-limite em que os profissionais se encontram, muitas vezes, inseridos.

Os valores no contexto relacional, normalmente, apontam o que é importante para cada ser humano. Os conflitos, entretanto, surgem quando insistimos em afirmar que aquilo que é importante para nós deve também o ser para o outro. O diálogo pode diminuir a distância e fortalecer os laços interdisciplinares; logo, o "diálogo não pode excluir o conflito, sob a pena de ser um diálogo ingênuo" . ${ }_{113}$ Também não se trata, aqui, de um diálogo romântico entre sujeito e objeto, mas entre sujeitos para a superação das diferenças e contradições. Assim, este texto tem como objetivo relatar como ocorreu a construção de um processo interdisciplinar, dialógico-reflexivo, com vistas à humanização do ambiente hospitalar.

\section{COMPROMISSO COM A HUMANI- ZAÇÃO: UMA VISÃO SISTÊMICA}

Os profissionais da saúde estabelecem uma relação entre si, na interação de todos com a cultura e a realidade concreta, num processo em constante transformação nos níveis micro e macro, nos quais a dinâmica da vida e da profissão ocorre mediante um movimento de reflexão e diálogo na ação e sobre a ação. Portanto, há um pensar sobre a ação, antes, durante e depois de esta ser concretizada, considerando que é intrínseco ao ser humano o estado de inquietação e de busca incessante de respostas aos desafios emergentes.

O profissional, inserido no contexto históricosocial-institucional, constrói o seu ser e o seu agir, através de relações interdisciplinares consistentes, construindo-se, efetivamente, como sujeito, na relação com os demais profissionais. Ou seja, no contato com os diversos saberes, o profissional terá maior chance de visualizar e encontrar estratégias de ação e enfrentamento coletivos para a resolução de problemas e, conseqüentemente, o desencadeamento de uma prática mais humanizada e humanizadora.

Para que exista um compromisso efetivo e consciente com a humanização, a realidade não pode ser percebida enquanto objeto pronto, estático e imutável. A realidade profissional e organizacional, todavia, deve ser percebida em sua totalidade e dinamicidade, já que suas partes se encontram em permanente interação. A ação não pode incidir apenas sobre as partes isoladas, mas sobre a totalidade, isto é, a partir de uma visão sistêmica, para que ocorra a transformação, ou melhor, a humanização como resultado de uma nova práxis. Não basta intervir sobre um determinado saber, como parte isolada da totalidade, é preciso visualizar o todo e estabelecer um espaço de interação interdisciplinar: "é transformando a totalidade que se transformam as partes". ${ }^{6: 21}$

Assim, se o compromisso é realmente com o ser humano, com a causa de sua humanização, ele necessita compreender o mundo que o cerca em sua profundidade e totalidade, para nela encontrar soluções e possibilidades de engajamento com a realidade do trabalho e, conseqüentemente, com a realidade subjetiva dos profissionais. Logo, o compromisso com a realidade profissional e institucional supõe um compromisso consciente com a humanização.

Em seu modo singular de apreender a realidade e o sujeito, inspira, nos profissionais desejosos de uma nova prática, uma ressignificação dos valores, crenças e princípios que norteiam a ética profissional. ${ }^{2}$ Nessa perspectiva, se a mudança ocorre mediante o diálogo e a reflexão crítica sobre a realidade concreta e a história, o processo de humanização deve ser, também, balizado por valores éticos e humanitários que buscam resgatar a essência do ser humano.

O compromisso com a humanização no ambiente hospitalar não deve ser considerado um ato passivo e estático, mas requer um processo permanente e gradual de ação-reflexão e inserção na realidade através do esforço dinâmico e participativo. $\mathrm{O}$ papel do trabalhador social que optou pela mudança deve ser o de estimular o processo de conscientização dos profissionais com quem trabalha, no sentido de valorizar potencialidades, estimular e provocar novas possibilidades de resgate dos valores humanos e sociais.

Em suma, compreender e analisar a realidade na ótica freireana requer, do profissional, não apenas conhecimento e inserção na realidade, mas, sobretudo, um compromisso com a transformação. Dessa maneira, não basta estimular e apontar novos caminhos de ressignificação e valoração da dignidade humana sem, contudo, libertar a subjetividade do misticismo e da alienação histórica, uma vez que esses escravizam o ser e o agir humanos. Enfim, requer dos profissionais o desvelamento da realidade concreta, para a superação constante da alienação e do conformismo, a fim de liberar a criatividade e a subjetividade. 


\section{TRAJETÓRIA METODOLÓGICA}

Utilizando situações vivenciais do grupo, Freire delineou sua proposta de trabalho, baseada em características tais como: ser ativo, criativo, dialógico e crítico, com o uso de técnicas participativas e mobilizadoras, capazes de revelar o potencial subjetivo e transformador dos sujeitos envolvidos no processo. Desse modo, os integrantes do processo são conduzidos - de forma lenta, mas contínua e dinâmi$\mathrm{ca}$ - a refletir sobre o cotidiano, oportunizando a partilha de experiências e expectativas e, no espaço interdisciplinar, crescer, sentir-se valorizado para, assim, transformar a realidade, com vistas à humanização.

O presente trabalho foi realizado em uma instituição hospitalar, localizada no extremo Sul do Rio Grande do Sul, entre os meses de julho de 2003 e julho de 2004, com/a partir de lideranças pertencentes à equipe multiprofissional da saúde, perfazendo, inicialmente, dezoito profissionais, entre enfermeiros, médicos, nutricionistas, farmacêuticos, psicólogos, assistentes sociais, contadores, administradores, economistas domésticas e outros, totalizando, ao final, 21 participantes.

A constituição da Equipe de Humanização objetivou constituir um espaço interdisciplinar, dialógico-reflexivo, com vistas à problematização da realidade concreta, no âmbito hospitalar, voltada tanto à assistência do usuário quanto, principalmente, às condições e relações de trabalho dos profissionais. A proposta partiu da idéia de que a mudança é possível e viável, à medida que se consegue ler o mundo a ser transformado para além das diferenças profissionais.

A escolha dos componentes da Equipe de Humanização deu-se através de convite pessoal, de modo que participasse, pelo menos, um profissional de cada serviço/saber disciplinar. A sua seleção intencional permitiu a escolha de profissionais para os quais se entendia que as palavras têm vida, porque dizem respeito ao seu trabalho, aos seus desejos, às suas inquietações e/ou pessoas que exercessem algum tipo de liderança nos diferentes setores. Não uma liderança qualquer, mas uma potencial liderança comprometida com o ser humano e nele centrada, capaz de encorajar a participação dos profissionais nas decisões e preocupada mais com as metas do que com os métodos. ${ }^{7}$

A proposta encontrou eco, sobretudo, na Política de Humanização da Assistência à Saúde (PHAS), iniciativa do Governo do Estado do Rio Grande do Sul que busca, em suas prioridades, melhorar as rela- ções interpessoais, a valorização do trabalho e a motivação profissional, a fim de conferir mais qualidade e humanismo às relações profissionais e, conseqüentemente, oportunizar um atendimento mais humanizado ao paciente. ${ }^{8}$

Para atender aos princípios propostos por Freire, os encontros quinzenais da Equipe de Humanização, de aproximadamente 90 minutos, se constituíram, essencialmente, em um espaço de partilha, convivência e crescimento. No intuito de tornar os encontros ainda mais dinâmicos, atrativos e participativos, seus integrantes foram estimulados a desenvolver dinâmicas interativas, mensagens, exercícios práticos e/ou outras técnicas que contribuíssem à sua reflexão e integração. Levando em conta os critérios éticos, foram seguidas as recomendações da Resolução n. 196/96, do Conselho Nacional de Saúde, bem como a solicitação de autorização ao Comitê de Ética em Pesquisa da instituição, para validar a proposta de trabalho e poder divulgar as informações.

Aos participantes, foram esclarecidos os objetivos e a metodologia proposta, além de ser assegurado o seu direito de acesso aos dados. $\mathrm{O}$ consentimento por escrito foi solicitado, com o propósito de cada um poder utilizar as informações, garantindo que a identidade seria mantida em sigilo e assegurada a liberdade de qualquer integrante deixar o grupo, se entendesse que seria melhor para si. Foi reforçada, também, a importância de manter o respeito às diferenças profissionais, valores, visão de mundo, mesmo que divergentes, havendo, dessa forma, o direito de cada um expressar-se livremente, porém, com responsabilidade e delicadeza.

\section{UNIVERSO TEMÁTICO: OS TEMAS GE- RADORES}

Um dos fundamentos metodológicos das práticas coletivas de transformação da realidade é orientar-se, não segundo um roteiro temático predefinido, mas com base em situações-limite à nossa volta. ${ }^{5}$ Assim, quando o problema aflora, surge também a oportunidade de questionamentos, reflexão, aprofundamento da consciência crítica e a capacidade de transformação. O desvelamento do universo temático, no espaço interdisciplinar, permitiu descobrir o núcleo de sentido que compõe uma comunicação ou que denota os valores de referência e os modelos de comportamento presentes no discurso do dia-a-dia.

Desse modo, emergiram temas geradores** e a

\footnotetext{
*Temas geradores - qualquer que seja a natureza de sua compreensão, como ação por eles provocada, contém em si a possibilidade de
} desdobrar-se em outros temas que, por sua vez, provocam novas reflexões e ações. ${ }^{5}$ 
criação de situações existenciais na equipe, as quais foram problematizadas em forma de debate e reflexão crítica, a fim de propor-se uma nova práxis. A participação ativa e criativa dos membros da equipe, na exploração de suas temáticas e a partir de numa operação de distanciamento do objeto, permitiu, ainda, uma operação coletiva sobre o objeto, favorecendo o aprofundamento da consciência crítica sobre a realidade a ser desvelada. Os temas geradores, ou as idéias-força inerentes a todo e qualquer processo de mudança, são categorias que refletem o pensar e o agir dos profissionais envolvidos. ${ }^{5}$ Desse modo, apresentamos os temas geradores que emergiram no círculo de cultura, isto é, nos encontros da Equipe de Humanização, ilustrando-os com falas significativas de participantes (e1; e2; e3...).

\section{Humanizar-se para humanizar}

Desenvolver o processo de humanização na instituição hospitalar, a partir da sensibilização dos profissionais e da gestão, representou um grande desafio e, ao mesmo tempo, uma grande meta para a equipe de humanização. A sensibilização e humanização, no entender da equipe, deveriam começar pelos seus próprios membros, pois "épreciso amadurecer esensibilizar os integrantes do grupo, antes de multiplicar o trabalho para a coletividade" (e1). Sensibilizar a equipe internamente, criar vínculos de coesão e convicção entre os integrantes e favorecer uma relação de respeito consigo mesmo e com o outro, ou seja, humanizar as relações entre os membros da própria equipe, constituiu-se em um pressuposto vital para mobilizar a coletividade: "precisamos respeitar os nossos limites. Não opodemos criticar o outro, sem antes conbecer mostrar oquepodeser diferente"(e2).

Analisar e compreender o mundo pessoal como pressuposto para compreender e transformar o mundo que nos cerca requer, acima de tudo, uma reflexão acerca de quem é o ser humano, que valores o definem como um ser de relações, que relações constituem os seres humanos entre si e com o universo, que atributos e potenciais o definem. Ainda, qual o papel da humanização nesse contexto complexo e evolutivo da espécie humana, ou seja, para onde tende a sua caminhada evolutiva? Importa que o processo de humanização inicie pelos integrantes da equipe. Em outras palavras: "a gente precisa se trabalhar para ser um reflexopositivo na vida dos outros. Foi muito bomentrar neste grupoeterum contato maiorcom a equipe multiprofissional. Mas, a relação mais difícilécom a equipe médica"(e3).

Superar os conflitos relacionais de maneira cons- trutiva e libertadora é sempre um desafio que envolve diálogo, respeito e conscientização das partes envolvidas. O resultado do conflito não é algum tipo de unidade imposta ou alienadora, mas, antes, uma unidade crítica e criativa capaz de impulsionar uma nova ação. O ser humano, naturalmente, carrega consigo contradições e incertezas, através da natureza animal comandada pelos instintos e de uma natureza consciente e reflexiva, capaz de sobrepor os instintos, os atributos mentais de inteligência, vontade, sensibilidade e interação. ${ }^{9}$ A partir desse movimento dinâmico de construção e/ou desconstrução de contradições e/ou incertezas, o ser humano é colocado, constantemente, diante de múltiplas escolhas. Quanto mais evoluirmos como humanos e conhecermos a fundo a natureza contraditória e limitada, tanto mais conscientes serão as escolhas e a possibilidade de transformar a história pessoal e o mundo que nos rodeia.

Os pressupostos de investigação, análise e construção do mundo pessoal são fundamentais para relacionar a consciência humana às questões de humanização. Se humanizar é também ser frágil, poder chorar, sentir o outro, ser vulnerável e, ao mesmo tempo, ter vigor para construir e traçar novos caminhos, é essencial que o ser humano se reconheça em suas potencialidades e fragilidades. Então, a humanização pode ser entendida como um "processo educacional dinâmicoepermanente"(e4).

No processo de construção e/ou desconstrução do mundo pessoal e social, a educação ocupa um lugar privilegiado, por ter, como elemento balizador, o ser humano que busca a superação de suas imperfeições, de seu saber relativo. A educação consiste em um processo no qual o ser humano se educa continuamente, através de um processo dialético com a sociedade, a partir de valores e critérios que a própria sociedade estabelece como elementares.

\section{O ser humano - um ser de relações dialógicas}

Paulo Freire, através do seu método de trabalho, insere o ser humano em um contexto cultural e democrático, no qual o valor do coletivo e a noção de equipe constituem o eixo central para qualquer processo de mudança. Dessa maneira, mostra-se pertinente a assertiva de que "épreciso trabalhar com a questão da humanização, mas, antes, precisamos aprender a trabalhar emequipe"(e1). O programa de humanização, portanto, necessita ser entendido como um processo de equipe, na qual "éimportante a representaç̧ão de todos os setores na equipe. É preciso que visualizemos omesmo horizonte"(e3), 
que tem na sua essência o ser humano como um ser de relações e o diálogo como seu componente motivacional. Logo, é na equipe que se dá o conhecimento global da realidade e a consolidação de uma participação efetiva, da mudança de percepção de uma realidade distorcida, bem como o enfrentamento das barreiras interdisciplinares.

Formar uma equipe não significa, apenas, agregar e somar funções para o alcance de um objetivo comum; no caso, o da humanização, representa, porém, aliar competências, compreender divergências e estabelecer um processo relacional integrador e problematizador, capaz de resgatar os sentimentos verdadeiramente humanos. A integração, nesse sentido, não significa uma simples adaptação, acomodação ou ajustamento das diferenças profissionais, o que caracterizaria um sintoma de desumanização, mas implica que tanto a visão de si mesmo como a do mundo não podem absolutizar-se. Ou seja, o debate das idéias, o desenvolvimento da capacidade criadora e a consciência crítica são elementos fundamentais para estabelecer o verdadeiro vínculo de interdependência e/ou de equipe, no espaço interdisciplinar. ${ }^{2}$

A criação dos grupos/equipes de humanização, na maioria das vezes, tem por objetivo auxiliar na mobilização de recursos subjetivos para melhor lidar com o cotidiano do trabalho. A denominação de núcleos de humanização, ao invés de grupos, denota que o núcleo favorece a explicitação, a comunicação e a reflexão sobre as situações do cotidiano. ${ }^{10} \mathrm{O}$ Círculo de Cultura denomina um espaço democrático e participativo, em que predominam as relações de diálogo e escuta. ${ }^{11}$ Não importa, porém, nesse contexto, a terminologia que queiramos adotar. Importam, sim, a conotação e a ênfase no processo enquanto proposta de construção participativa.

O ser humano é um ser de relações no mundo e com os outros. Desse modo, abre-se ao desconhecido, às aventuras, correndo o mundo para transformálo. Consoante a essa idéia, uma das integrantes da equipe lembrou que "a gente, que possui um cargo de chefia, nem sempreconseguelidar com as diferençasprofissionais[...]. Para mim, fez muito bem entrarnesta equipe" (e5). Transformando-se a si próprio, o ser humano assume a condição de ser protagonista, porque já não se satisfaz em assistir, mas quer participar, partilhar, construir. ${ }^{12}$ Logo, para que a humanização desafie os profissionais da saúde a repensar a postura profissional, é imprescindível a criação de um espaço interdisciplinar para a partilha, a convivência e o estreitamento do vínculo afetivo.

\section{A humanização a partir do acolhimento e do vínculo afetivo}

O processo de humanização passa, também, pela percepção do ser humano em todas as suas dimensões e inter-relações. Os laços afetivos tornam as pessoas e as situações preciosas, humanas e portadoras de valores éticos e humanos. No entanto, ainda persiste o receio em expressá-los de forma madura e consciente, ou seja, "temos, muitas vezes, receio de demonstrar um gesto de afeto. Pequenosgestossão significativos, quando realizados com o coração" (e8). Contudo, é preciso criar um ambiente para a expressão de sentimentos, uma vez que é na sua manifestação que o ser humano se torna sensível ao que está à sua volta. É o sentimento humano que nos une às coisas e nos envolve com as pessoas e suscita abertura e acolhimento do diferente. ${ }^{13}$

Para despertar e aprofundar o espírito de equipe, a partir do estreitamento dos laços humanos e afetivos entre os integrantes, e na expectativa de minimizar as diferenças profissionais e sociais, estimulou-se, no final de cada encontro, o gesto do abraço como forma expressiva de comunicação e afeto, assim como o fortalecimento de sentimentos de solidariedade, respeito e compreensão, considerados, no contexto da humanização, fundamentais para o despertar da sensibilidade humana de uns para com os outros. O abraço emerge do próprio ato de existir no mundo com os outros, já que não existimos, coexistimos e convivemos com as realidades mais adversas. Assim, é a expressão de um sentimento que perpassa e capacita as relações humanas.

Para tanto, é imprescindível, no contexto da humanização, construir o mundo pessoal e coletivo, a partir de laços afetivos, que fazem preciosas, portadoras de valor, as pessoas e as situações. O abraço é um desses atos que revelam a capacidade de o ser humano de emocionar-se, de envolver-se e comprometer-se afetivamente - ações, portanto, indispensáveis para a conquista de um novo espaço no contexto interdisciplinar da saúde. ${ }^{13}$

O abraço, entretanto, não se limitou à equipe de humanização. Foi criado e incentivado o dia do abraço em todo o ambiente hospitalar: dia dezessete de cada mês, no intuito de estreitar os vínculos humanos e profissionais entre os diversos setores. A data foi escolhida aleatoriamente pela equipe, e a idéia foi bem aceita por todos, sendo que a mobilização da proposta se deu, de forma espontânea e voluntária, entre os trabalhadores e, inclusive, entre os pacientes.

Inicialmente, chamaram a atenção da equipe as 
diferentes expressões e respostas coletivas ao abraço. Enquanto alguns demonstravam estranheza, outros demonstravam reconhecimento e calor humano e, ainda, outros, diziam: um abraço!'Mas, hoje nãoéo men aniversário! Ou, então: mas... que dia éboje? O dia do abraço, portanto, mesmo sendo um dia qualquer, buscou dar um sentido especial a cada ser humano, no seu mundo de relações. A humanização, nesse cenário, estimula o cultivo de relações profissionais próximas e afetivas, a fim de compreender o dia-a-dia em sua singularidade. Em outras palavras, "precisamos viver a vida com a compreensão de que cada dia é único e especial, não guardando nada para uma ocasião especial". ${ }^{14.88}$

Todo dia, de fato, reserva-nos uma ocasião e/ ou um encontro especial. Dessa maneira, as relações humanas são especiais e possibilitam compreender a força que há num toque, num abraço e num gesto de acolhida. No entanto, para tornar as relações humanas especiais, bastam pequenos reconhecimentos, pequenos gestos e, muitas vezes, pequenas relações de cuidado. O ser humano é, por natureza, um ser de cuidado; mais ainda, sua essência se encontra no cuidado. Colocar cuidado em tudo o que projeta e faz se constitui em uma característica singular do ser humano. ${ }^{13}$

\section{A humanização passa pela comunicação}

Nas relações de trabalho, bem como em todas as relações que o ser humano estabelece, não existe humanização sem uma comunicação eficiente e eficaz. A comunicação, no contexto da humanização, não é diferente; ela pressupõe uma relação "com" o outro, em vez de "para" o outro, o que representa a soma das expressões verbais e não-verbais. ${ }^{15}$ Desse modo, é fundamental, para a construção de um senso de solidariedade, a comunicação dos sentimentos, das atitudes pessoais em relação ao se humana.

"A bumanização começa pela comunicação"(e10). Foi assim que a equipe definiu e sintetizou um dos primeiros encontros grupais, evidenciando a importância da comunicação no contexto interdisciplinar e intersetorial, por entender que, sem comunicação não existe integração, nem senso de equipe e, muito menos, cuidado integral. Por isso, concluiu que " $a$ comunicação deve começar pelos integrantes da nossa equipe de bumanização"(e12;e15).

A comunicação transforma, essencialmente, os homens e mulheres em sujeitos. ${ }^{2}$ Enquanto ferramenta humana básica, a comunicação adquire, na concepção de Freire, uma dimensão política através do caráter problematizador e gerador de reflexão. Conseqüen- temente, a reflexão e a ação constituem as duas dimensões essenciais da comunicação, tendo em vista que não é no silêncio que o ser humano se desenvolve, mas na palavra, no trabalho, na ação-reflexão.

A existência do ser humano no mundo revela todo um dinamismo relacional, um modo de ser e realizar-se na realidade concreta. A sua existência não pode ser muda, silenciosa, ou nutrida por um simples quefazer sem reflexão. "Existir humanamente, é pronunciar o mundo, é modificá-lo. O mundo pronunciado, por sua vez, se volta problematizado aos sujeitos pronunciantes, a exigir deles novo pronunciar".6.78

Quando identificadas as dificuldades intersetoriais e, ao associá-las à comunicação, houve consenso de que "precisamos melhorar acomunicaşãoecriar um elodeligação e confiança" (e2; e5; e9). Comentários e discussões relacionados à deficiência de comunicação - entre os profissionais e entre os setores - foram muito freqüentes nos encontros da equipe. Com reflexão, diálogo e partilha, a equipe, porém, compreendeu que era necessário estreitar os laços afetivos, conhecer a realidade de cada setor e estabelecer "uma rede de comunicação" (e16), dando ênfase à divulgação de conquistas e/ou aspectos construtivos, ao invés de comentários depreciativos e, por vezes, antiéticos.

As reflexões em torno da temática da comunicação suscitaram que "precisamos melhorar a comunicação no hospital [...]. Às vezes, as pessoas têm atitudes que nem sempregostariam deter, masagem involuntariamente, porque, na maioriadas vezes, possuem problemas deordem afetiva" (e11; e17). Realizado o diagnóstico situacional e compreendida uma das grandes dificuldades de ordem relacional, foi preciso, então, traçar uma meta. Estabelecer uma rede de comunicação intersetorial institucionalizada, conectada por laços de compreensão, diálogo e escuta. A comunicação efetiva e eficiente é, por conseqüência, expressão de humanização. Enfim, seja por meio de palavras faladas e escritas, seja por meio de gestos, expressões faciais e corporais, o trabalho na área da saúde exige do profissional o conhecimento aprofundado desse processo chamado comunicação interpessoal. ${ }^{15}$

\section{CONSIDERAÇÕES FINAIS}

O método de desenvolvimento, isto é, de planejamento, implementação e avaliação do processo a partir da Equipe de Humanização foi, sem dúvida, uma estratégia de grandes e profundas descobertas em nível pessoal, coletivo e institucional. Forças distintas estavam, continuamente, em movimento, e o pro- 
cesso passou a ser irreversível. Diferente de outros programas e/ou frentes de trabalho, o processo de humanização, a partir da equipe interdisciplinar, primou, essencialmente, pelas relações de contato, de afeto e de valoração da pessoa humana enquanto sujeito histórico e social. Nos encontros da equipe, existiu a certeza de termos sido sempre acrescidos de algo, mesmo que, muitas vezes, não tivéssemos suficiente consciência do que se constituía, mas sabíamos apenas que não éramos mais os mesmos. A humanização buscou, dessa maneira, sinalizar e contribuir para a promoção de novas possibilidades e práticas do ser e fazer, além de produzir sujeitos ativos e agentes de mudanças.

Envolver a coletividade, estimular formas criativas e estabelecer estratégias problematizadoras de comprometimento e conscientização representaram, no processo, algumas das importantes funções da equipe de humanização. Despertar um clima de respeito, de confiança e reciprocidade constituiu-se, da mesma forma, num espaço propício para o fortalecimento das relações profissionais e, conseqüentemente, na provocação de uma nova prática.

Os profissionais da equipe de saúde compreenderam, no transcorrer do processo, que a humanização significa aliar competência técnica à ternura humana e permitir que o coração se manifeste nas relações de trabalho do dia-a-dia. Compreenderam, ainda, a humanização enquanto espaço de solidariedade, respeito, diálogo, preocupação com o outro, assim como espaço de promoção de relações mais efetivas entre os colegas, considerando o paciente como a razão de ser da existência do hospital. Nesse sentido, o processo de sensibilização e conscientização é fundamental para humanizar as relações dos profissionais entre si e, por consequência, destes com os pacientes.

Em suma, desencadear um processo de humanização no ambiente hospitalar não consiste em mágica extraordinária ou no investimento de custos elevados para a instituição. Muito mais do que mudanças e adaptações do ambiente físico são necessárias mudanças na prática dos profissionais. Finalmente, cabe enfatizar o ser e o fazer profissionais, ressaltando, a ética, ao respeito e à dignidade da pessoa humana. Todas as iniciativas são válidas, quando se fala em humanização, desde que haja sensibilização e problematização da realidade concreta, a partir de um espaço interdisciplinar.

\section{REFERÊNCIAS}

1 Pessini L. Humanização da dor e do sofrimento humanos na área da saúde. In: Pessini L., Bertachini L, organizadores. Humanização e cuidados paliativos. São Paulo: Loyola; 2004. p.11-28.

2 Freire P. Pedagogia da autonomia: saber necessário à prática educativa. Rio de Janeiro: Paze Terra; 1993.

3 Silveira RS, Lunardi VL. A problematização do cotidiano do trabalho da enfermagem. Texto Contexto Enferm. 2000 Mai-Ago; 9 (2): 447-58.

4 Vasconcelos EM. Complexidade e pesquisa interdisciplinar Epistemologia e metodologia operativa. Petrópolis: Vozes; 2002.

5 Freire P. Pedagogia do oprimido. 17a ed. Rio de Janeiro: Paze Terra; 1987.

6 Gadotti M. Educação e mudança. Rio de Janeiro: Paz e Terra; 1979.

7 Chiavenato I. Gerenciando pessoas. O passo decisivo para a administração participativa. São Paulo: Makron Books; 1992.

8 Secretaria da Saúde do Rio Grande do Sul (BR). Humaniza saúde: política de humanização da assistência à saúde. Porto Alegre: Secretaria da Saúde; 2003.

9 Arruda M. Humanizando o infra-humano: a formação do ser humano integral: homo evolutivo, práxis e economia solidária. Rio de Janeiro: Vozes; 2003.

10Faiman CS, Danesi D, Rios IC, Zaher VL. Os cuidadores: a prática clínica dos profissionais da saúde. $O$ Mundo da Saúde. 2003 Abr-Jun; 27 (2): 254-7.

11 Gadotti M. Paulo Freire: uma bibliografia. São Paulo: Cortez; 1996.

12 Freire P. Conscientização: teoria e prática da libertação. 3a ed. São Paulo: Morais; 1980.

13 Boff L. Saber cuidar: ética do humano - compaixão pela terra. Rio de Janeiro: Vozes; 1999.

14 Silva MJP. O Amor é o caminho: maneiras de cuidar. São Paulo: Gente; 2002.

15 Silva MJP. Comunicação tem remédio: a comunicação nas relações interpessoais em saúde. São Paulo: Gente; 1996. 